\title{
Direct Mechanical Stimulation of Stem Cells: A Beating Electromechanically Active Scaffold for Cardiac Tissue Engineering
}

Amy Gelmi, Artur Cieslar-Pobuda, Ebo de Muinck, Marek Jan Los, Mehrdad Rafat and Edwin Jager

\section{Linköping University Post Print}

\section{Tweet}

N.B.: When citing this work, cite the original article.

Original Publication:

Amy Gelmi, Artur Cieslar-Pobuda, Ebo de Muinck, Marek Jan Los, Mehrdad Rafat and Edwin Jager, Direct Mechanical Stimulation of Stem Cells: A Beating Electromechanically Active Scaffold for Cardiac Tissue Engineering, 2016, Advanced Healthcare Materials, (5), 12, 14711480 .

http://dx.doi.org/10.1002/adhm.201600307

Copyright: Wiley: 12 months

http://eu.wiley.com/WileyCDA/

Postprint available at: Linköping University Electronic Press

http://urn.kb.se/resolve?urn=urn:nbn:se:liu:diva-130427 


\section{Direct mechanical stimulation of stem cells: a beating electro-mechanically active scaffold for cardiac tissue engineering}

Amy Gelmi, Artur Cieslar-Pobuda, Ebo de Muinck, Marek Los, Mehrdad Rafat, Edwin W.H. Jager*

Dr. A. Gelmi†, Dr. E.W.H. Jager

Department of Physics, Chemistry and Biology, Linköping University, 58183 Linköping, Sweden

† Currently at Department of Materials, Imperial College London, SW27AZ London, United Kingdom

E-mail: edwin.jager@liu.se

Dr. A. Cieslar-Pobuda,ł, Prof. M. Los\$

Department of Clinical and Experimental Medicine, Division of Cell Biology, Linköping University Hospital, 58185 Linköping, Sweden

¥ Currently at Institute of Automatic Control, Silesian University of Technology, Akademicka 16, 44-100

Gliwice, Poland

\$ Currently at Department of Pathology, Pomeranian Medical University, 71-252 Szczecin, Poland

Prof. E. de Muinck

Department of Cardiology, Linköping University Hospital, 58185 Linköping, Sweden

Faculty of Medicine and Health Sciences, Division of Cardiovascular Medicine, 58185 Linköping, Sweden

Dr. M. Rafat

Linkoping University, Department of Biomedical Engineering, 58185 Linköping, Sweden

Keywords: conductive polymer, scaffold, tissue engineering, stem cell, actuators

\section{Abstract}

The combination of stem cell therapy with a supportive scaffold is a promising approach to improving cardiac tissue engineering. Stem cell therapy can be used to repair non-functioning heart tissue and achieve myocardial regeneration, and scaffold materials can be utilised in order to successfully deliver and support stem cells in vivo. Current research describes passive scaffold materials; here we present an electroactive scaffold that provides electrical, mechanical, and topographical cues to induced human pluripotent stem cells (iPS). The poly(lactic-co-glycolic acid) (PLGA) fibre scaffold coated with conductive polymer Polypyrrole (PPy) is capable of delivering direct electrical and mechanical stimulation to the iPS. The electroactive scaffolds demonstrated no cytotoxic effects on the iPS, as well as an increased expression of cardiac markers for both stimulated and unstimulated protocols. This study demonstrates the first application of PPy as a supportive electroactive material for iPS, and the first development of a fibre scaffold capable of dynamic mechanical actuation. 


\section{Introduction}

Mortality from myocardial infarction (MI), or heart attack, is declining in high-income countries, but the trade-off has been a healthcare financial burden reaching epidemic proportions with an estimated 38 million patients affected by MI worldwide. ${ }^{[1,2]} \mathrm{MI}$ is a blockage of a coronary artery by a blood clot causing death of downstream cardiomyocytes. The wound healing response results in the replacement of dead cardiac tissue by noncontractile scar tissue, leading to a loss of cardiac pumping capacity and consequently to congestive heart failure. Despite the therapeutic advances during the acute phase of MI, the options for chronic care of MI survivors are very limited. ${ }^{[2]}$ Thus, there is an enormous unmet need for novel strategies to repair the failing heart. Heart transplantation is severely limited by the availability of sufficient donor organs, and the field of stem cell therapy offers an alternative solution with the ability to regenerate and repair the non-contractile tissue. However, clinical trials of injection methods for cardiac stem cell delivery have produced disappointing results with low stem cell survival rates, poor retention and little improvement in cardiac functionality. ${ }^{[3,4]}$

We aim to address this inadequacy by developing a 3-D multi-functional scaffold that provides an appropriate microenvironment to promote stem cell survival and differentiation into mature cardiomyocytes, and pre- and post- implantation retention. Providing a biophysical and biochemical microenvironment for the stem cells will enhance the regeneration of the host tissue and cardiac function, and subsequently improve health outcomes. Even a modest 5\% improvement in cardiac ejection fraction is sufficient to impact survival in MI patients ${ }^{[5]}$ and will have enormous positive impact on both human health and health care costs.

Here we present an electro-mechanically active fibre (EMAF) scaffold, which can be equipped in any standard petri-dish or well-plate with standard cell culture media. The EMAF provides not only electrical but also direct mechanical stimulation, and is the first fibrous 
material able to deliver both types of stimulation to seeded cells. In order to demonstrate the feasibility of the EMAF to successfully support and directly stimulate cells, human induced pluripotent stem cells (iPS) were seeded on the scaffolds for a preliminary study. In recent years iPS have shown promise in tissue engineering and regenerative medicine for treatment of heart diseases. ${ }^{[6]}$ IPS cells are generated by introducing specific transcription factors (e.g. Oct4, Sox2, Klf4 and c-myc) into adult somatic cells, which reprogram somatic cells into an undifferentiated, pluripotent state similar to embryonic stem cells (ESCs). ${ }^{[7]}$ The resulting cells have the ability to differentiate into all three germ layers, and avoid ethical issues associated with ESCs as no oocytes or embryos are used. Furthermore, iPS can be developed from patient-derived cells, eliminating risk of immune rejection which is hugely beneficial for tissue regeneration therapy.

The utlization of 3-D scaffold materials as delivery platforms for stem cells has proved to be an effective approach, ${ }^{[8-10]}$ with electrospun fibrous scaffolds demonstrating improved cell adhesion and direct growth due to the similarity to the fibrous structure of the extra-cellular matrix (ECM). ${ }^{[11-13]}$ Electrically conductive scaffolds have also demonstrated enhanced cardiac cell adhesion and growth, primarily attributed to the ability of the scaffold to provide a conductive microenvironment for cardiac cells. ${ }^{[14,15]}$ The electro-mechanical properties of the EMAF scaffold are capable of providing this conductive microenvironment in addition to direct dual electrical and mechanical stimulation, which has been shown to guide the differentiation of stem cells into (cardio-)myocytes. ${ }^{[16,17]}$ Dual stimulation approaches to tissue engineering for cardiac tissue has been gaining traction, however further optimisation and improved experimental design of this type of stimulation is still needed. ${ }^{[18]}$ These electromechanical properties are incorporated via a conformal coating of conducting polymer Polypyrrole (PPy) around the fibres within the electrospun scaffold. PPy provides a noncytotoxic and biocompatible surface for many cell types, ${ }^{[19,20]}$ and as a preface to this study 
we investigated the response of cardiac and endothelial progenitor cells to PPy materials with different anionic dopants, ${ }^{[21]}$ and hence have focused here on the dopant dodecylbenzenesulfonate (DBS). Furthermore, PPy undergoes a reversible volume change when electrically stimulated which generates mechanical actuation, and thus mechanical stimulation; this remarkable property has yet to be exploited in conductive scaffold materials. ${ }^{[22]}$ Mechanical stimulation is an important external stimulus for stem cell differentiation, ${ }^{[23]}$ and vascular cells demonstrate sensitivity to mechanical stimulation that mimics pulse and shear fluid mechanics. ${ }^{[24]}$ It is this mechanical actuation that adds an entirely original aspect to the EMAF scaffolds, providing direct mechanical stimulation to individual cells.

\section{Results}

\subsection{Electroactive Scaffold Characterisation}

PLGA was chosen as the electrospun scaffold material, ${ }^{[11,25,26]}$ and is well-established as a biocompatible, non-toxic polymer suitable for in vivo use. ${ }^{[27]}$ The electrospinning of the PLGA solution produced fiber mats approximately $30 \mu \mathrm{m}$ in thickness comprised of individual fibers with a mean diameter of $2.27 \mu \mathrm{m}(\mathrm{s} . \mathrm{d}=0.95, \mathrm{~N}=330$, s.e. \pm 0.05$)$. The morphology of the PLGA fibers shows a smooth featureless surface (Figure 1A, i), and the fibers are understandably non-conductive. In order to coat the PLGA scaffolds with PPy(DBS) we have developed a two-step approach for PPy deposition; an initial vapour phase polymerization (VPP) step coats the PLGA fibres with a thin, conductive layer of PPy $(\mathrm{Cl})$. The VPP coated fibres are then coated using electrochemical polymerization (ECP) in an aqueous pyrrole monomer solution with NaDBS to produce a thicker, more controlled, functional coating of PPy with the desired dopant DBS. DBS also has several advantages as a dopant in PPy beyond proven biocompatibility; being an immobile anion within the PPy structure the polymer is stable and DBS will not leach, and PPy(DBS) is known to perform as 
an excellent actuator. ${ }^{[28,29]}$. The actuation is based on volume change is driven by the movement of ions from the surrounding electrolyte in and out of the polymer to counteract the charge imbalance of the PPy backbone induced by the applied potential. ${ }^{[30,31]}$ The twostep PPy coating process is needed to produce PLGA fibers with an encompassing electroactive PPy(DBS) shell.

The initial VPP step was successful in providing an initial conformal conductive PPy layer around individual fibers (Fig 1A, ii). The PPy coating is smooth and there is no observable change to the fiber surface morphology, however the mean diameter of the fibers is increased to $2.90 \mu \mathrm{m}$ ( $\mathrm{s} . \mathrm{d}=0.97, \mathrm{~N}=425$, s.e. \pm 0.05$)$. Thus, the average thickness of the VPP layer is calculated to be $320 \pm 20 \mathrm{~nm}$. The short term ECP coating of 10 minutes did not result in a significant increase in the diameter of the fibres with a value of $2.91 \mu \mathrm{m}(\mathrm{s} . \mathrm{d}=1.03, \mathrm{~N}=308$, s.e. \pm 0.06), and a calculated thickness of $320 \pm 20 \mathrm{~nm}$. The PPy(DBS) coating on the fibres (Figure 1A, iii) displays the typical 'cauliflower' morphology as the thin 'patchy' layer of polymer is deposited on the VPP coating. The longer ECP coating time of 30 minutes results in a visibly thicker layer of $\mathrm{PPy}(\mathrm{DBS}$ ) (Fig 1A, iv) and a significant diameter increase to 3.24 $\mu \mathrm{m}$ (s.d=1.05, $\mathrm{N}=366$, s.e. \pm 0.06$)$, with a calculated PPy(DBS) thickness of $0.49 \pm 0.02 \mu \mathrm{m}$. As can be seen in Figure 1D, the growth of PPy(DBS) on the fibres shows an expected increase in charge over time, with the rate of charge increasing as more $\mathrm{PPy}(\mathrm{DBS})$ is deposited on the VPP coated fibres, due to increasing conductivity of the fibres. Figure 1E displays cyclic voltammetry (CV) graphs of VPP, 10 min, and 30 min ECP coated fibres from the same electrospun sample. The CVs further illustrates the increasing electroactivity of the fibres indicating an increasing thickness of PPy(DBS). As the thickness of the PPy(DBS) increases, the capacitance of the fibre materials increases as well as seen by the change in peak width from each samples.

\subsection{Electroactive Fibre Degradation}


The impact of in vitro conditions on the fibres was assessed for physical and conductive degradation. The fibre samples, plain PLGA, 10 and 30 min ECP PPy(DBS), were incubated in PBS for 7 days at $37^{\circ} \mathrm{C}$ and $5 \% \mathrm{CO}_{2}$. After the 7 days incubation of the PLGA fibres (Figure 2A) appear to have eroded, resulting in the fibre morphology coalescing. The hydrolytic degradation of PLGA when exposed to water is well understood, and PLGA (50:50) fibre structure tends to disintegrate after approximately 20 days under these incubation conditions. ${ }^{[32]}$ The 10 min ECP coated fibres (Figure 2B) show a change in morphology; the fibres begin to 'bulge' with small holes and dimples appearing on the fibre surface. The PPy layer is still visible over the fibres, which is also evidenced by the black visual appearance of the fibre materials (not shown). The 30 min ECP coated fibres (Figure 2C) show the fibres are similar in shape to the pristine fibres (Figure 1), but there are many dimples across the surface of the fibres. The inserted image demonstrated that the dimples are collapsed areas of PPy(DBS), indicating that the PLGA core within is degrading and not the PPy(DBS) coating. The electroactivity of the materials was also tested under in vitro conditions to confirm that the conductive integrity of the coated fibres is retained after incubation. Figure 2D displays a representative current response of 10 and 30 min ECP coated fibres from initial biphasic stimulation at a frequency of $0.05 \mathrm{~Hz}$ with a range of $0.2 \mathrm{~V}$ to $-1 \mathrm{~V}$ for 600 seconds (after 3 days incubation in differential media). The 10 min ECP fibres displayed a greater current response compared to the 30 min ECP fibres, with currents ranging from 3 to $6 \mathrm{~mA}$ compared to 0.5 to $2 \mathrm{~mA}$ respectively. After a total of 7 days in differential media, including 3 consecutive days of biphasic stimulation, the current response was reduced to a range of 0.2 to $1 \mathrm{~mA}$ for $10 \mathrm{~min}$ ECP fibres and 0.2 to $0.3 \mathrm{~mA}$ for $30 \mathrm{~min}$ ECP fibres.

\subsection{Mechanical Actuation}


The ability of the 30 min ECP PPy(DBS) coated fibres to mechanically actuate was recorded using high frame rate optical bright field microscopy. The volume change of the individual fibres of the 30 min ECP PPy(DBS) scaffolds and the overall motion of the scaffold itself is clearly visible as seen in the recorded video (Movie S1). The 10 min ECP PPy(DBS) fibres did not mechanically actuate on a scale quantifiable by optical microscopy; PPy can electromechanically actuate down to the nanoscale. ${ }^{[33]}$ The changes in the fibre area were quantified and correlated with simultaneous applied biphasic potential stimulation $(0.2 \mathrm{~V}$ to $1 \mathrm{~V}$ ) at three frequencies, $0.05,0.1$, and $0.2 \mathrm{~Hz}$. The actuative response of the $30 \mathrm{~min}$ ECP PPy(DBS) for the three frequencies (Figure 3A) shows a distinct and cyclical actuation (Movie S1). The calculated PPy(DBS) area change shows the greatest actuation with $0.05 \mathrm{~Hz}$ stimulation ( 6-8\%), and as expected the higher frequency stimulation display lower actuation (2-3\% for $0.1 \mathrm{~Hz}$ and $1-2 \%$ for $0.2 \mathrm{~Hz})$. The response of the volume change with the current (Figure 3B) shows a typical diffusion expansion of PPy during oxidation ${ }^{[33]}$, with the PPy(DBS) not reaching maximum volume change as indicated by the continued expansion during the slowest stimulation frequency of $0.05 \mathrm{~Hz}$. This effect of stimulation frequency on the maximum expansion of PPy has been noticed before. ${ }^{[34,35]}$ Actuation analysis of individual fibres was also possible through cross sectional analysis of the optical video stills. An example analysis of a single fibre (Figure 3C) shows that morphology and volume change of a fibre during $0.05 \mathrm{~Hz}$ stimulation. The cross section clearly shows a change in the thickness of the fibre (Figure 3D). At $0.05 \mathrm{~Hz}$ the thickness change of the calculated PPy(DBS) layer is 22\%; at $0.1 \mathrm{~Hz}$ the change is $\sim 10 \%$ and at $0.2 \mathrm{~Hz}$ the change is $\sim 5 \%$. The $22 \%$ radial thickness change of the PPy coating is in agreement with previous results that show a large perpendicular volume change of PPy(DBS) specifically. ${ }^{[34,36]}$

\subsection{Stem Cell Stimulation}


The fibre materials both as plain PLGA and ECP PPy(DBS) coated were investigated for compatibility with iPS and possible induction of cell differentiation. The iPS were grown on the fibres and stained for live/dead and actin (Figure 4A, B, C). The live/dead staining reveals that the iPS partially retain the 'clumping' from when they are seeded onto the materials in clusters of cells. More importantly, ECP PPy(DBS) coated fibres show excellent biocompatibility, with only few dead cells (stained red) detected (Figure 4A.i, B.i, C.i), consistent with normal cell death rate during culturing of iPS. Due to the three dimensional nature of the fibre materials it was difficult to image the iPS on a single focal plane. The live/dead staining shows no difference between the PLGA and ECP PPy(DBS) coated fibres, indicating that ECP PPy(DBS) coating does not adversely affect the survival of the cells. The actin staining highlighted the spreading of the iPS across the fibre materials for 10 min ECP, 30 min ECP, and PLGA (Figure 4A.iii, 4B.iii, 4C.ii, respectively). The actin filaments appear to be elongating and finding focal binding points across the fibres. The example SEM images of the iPS on 10 min ECP (Figure 4D.i) demonstrate that the cells are able to grow along and spread across the fibre structure, with morphology suggesting no potential repelling or toxic effects of the substrate.

A $0.05 \mathrm{~Hz}$ biphasic stimulation protocol was also applied to the iPS cells via the ECP scaffolds for maximum mechanical actuation, and the cells were analysed using live/dead staining (Figure 4A.i \& ii; Figure 4B.i \& ii), actin filaments staining (Figure 4A.iii \& iv; Figure 4B.iii \& iv) and gene expression (Figure 4E). Comparison between electromechanically unstimulated and stimulated iPS cells grown on ECP PPy(DBS) scaffolds show no adverse, toxic effects (low fraction of dead cells, Figure S1), and no negative influence on proliferation as the density of cells on stimulated and unstimulated samples is similar (Figure 4A.ii, 4B. ii). The stimulation also does not change cells 
morphology (Figure 4A.iv, 4B.iv, 4D. ii). It was however observed that iPS cells cultured and stimulated on 10 min ECP scaffolds look more spread and exhibit more smooth muscle-like morphology (Figure 4A.iv) than the unstimulated cells. Gene expression analysis reveals that differentiation of iPS cells into cardiomyocytes can be successfully achieved using both PLGA and ECP PPy(DBS) scaffolds (Fig, 4E). iPS cells grown in differentiation medium on stimulated and unstimulated scaffolds show elevated expression of cardiac markers: Actinin, NKX2.5, GATA4, Myh6 and decreased level of stemness factors: Oct4, Nanog when compared to undifferentiated iPS cells (Fig, 4E. i). The real time quantitative reverse transcription polymerase chain reaction (RT-qPCR) analysis (Fig, 4E. ii) demonstrates that cells grown on 30 min ECP scaffolds are characterized by elevated expression of Actinin, NKX2.5, GATA4 and Oct4 as compared to cells cultured on PLGA.

\section{Discussion}

The design of the electroactive scaffolds has produced a stable, conformal coating of PPy over PLGA fibres, with a controllable thickness. The 3-dimensional structure of the electrospun PLGA provides not only a material for cells to grow into and around, but will also allow for the electromechanical stimulation to be applied omni-directionally to the cells. Current research has only investigated uni- and equi-axial mechanical stimulation of cells using bulk substrate-flexing techniques, and so this work offers a new approach of delivering direct mechanical stimulation, easily integrated in standard petri-dishes and cell culture plates. The fibres are electro-mechanically active and behave in an expected manner for PPy(DBS). PPy synthesized with a large surfactant counterion such as DBS has been proven to be very stable, both in air and in aqueous solution. The bulky DBS molecule results in higher hydrolytic stability, as well as preserving the conductivity of the polymer. ${ }^{[37,38]}$ Hence the PPy(DBS) coating appears to limit the degradation of the PLGA core material, protecting it from the hydrolytic process. The thinner 'patchy' 10 min ECP coating allows for 
degradation of the PLGA, changing the morphology of the fibres and causing small defects in the PPy(DBS) layer, while the thicker 30 min ECP coating appears to limit degradation; fibre morphology is retained and the PPy(DBS) coating remains intact. The difference in current response between the 10 and 30 min ECP fibres can be attributed to the difference in thickness of the PPy(DBS) coating; the resistance is increased for the thicker 30 min ECP coating (also observed in the slope of the CV in Figure 1E) as the thicker fibres impede the flow of ions throughout the scaffold structure compared to the thinner 10 min ECP coating. The reduction in current response over incubation time can be partially attributed to 'biofouling' of the fibre scaffolds due to the adsorption of biomolecules in the media, such as proteins, onto the polymer surface. The adsorption of these biomolecules, as well as the presence of the adhered iPS cells, will impede the ionic charge flow from the PPy during electrical stimulation. The impact of reduction and oxidation of PPy on protein adsorption has also been well characterized, ${ }^{[39,40]}$ and hence the electrical stimulation may be enhancing the amount of protein adsorbed to the fibres compared to unstimulated fibres. However, a study on the cumulative effect of cyclical redox on protein adhesion has not yet been presented. The degradation of the PPy(DBS) coated fibres will also contribute to the reduction of the current response; breaks in the PPy(DBS) coating due to the 'bulging' PLGA core, and areas of collapsed PPy(DBS) defects will increase the overall resistance of the polymer. The ability of the PPy coated fibres to actuate is a unique feature to these electroactive scaffolds, compared to current designs of artificial scaffolds for cell stimulation. The volume change is driven by the movement of ions from the surrounding electrolyte in and out of the polymer to counteract the charge imbalance of the PPy backbone induced by the applied potential. ${ }^{[31,41]}$ The rate of diffusion of electrolytic ions present in the PBS solution is a controlling factor for the rate of actuation; as the stimulation frequency increases the PPy(DBS) is time-limited in the volume of ions that can diffuse into the polymer. Hence, 
when applying these fibres for direct mechanical actuation a slower frequency will maximise the volume change of the fibres, while a faster frequency will minimise the direct mechanical stimulation applied to cells.

Previous studies have applied mechanical stimulation to stem cells using a range of strain, frequency, and duration. Studies involving the use of bulk substrate-flexing techniques to deliver uni- and equi-axial mechanical stimulation to stem cells have demonstrated a strong influence on cell fate. ${ }^{[16,42,43]}$ Direct uni-axial mechanical stimulation to individual epithelial cells has been performed using PPy microactuators, with a clear, quantitative response from the cells. ${ }^{[44]}$ Our approach delivers direct omni-directional mechanical stimulation to individual cells. One method of local stress, magnetic twisting cytometry, observed that local, small cyclical stress of $17.5 \mathrm{~Pa}$ at $0.3 \mathrm{~Hz}$ for $60 \mathrm{~min}$ applied to mouse embryonic stem cells triggered down-regulation of the oct3/4 gene, ${ }^{[45]}$ a signal of differentiation. This study demonstrated that local stimulation will also directly trigger a response from cells, however this method cannot be applied to many individual cells simultaneously in bulk, unlike the EMAF. Frequencies within the range of 0.3 to $1 \mathrm{~Hz}$ are commonly used as they are analogous to the frequency of a beating heart, an important factor to which these EMAF have the capacity to produce. The calculated strain applied by the PPy(DBS) scaffold at $0.05 \mathrm{~Hz}$ ( 6$8 \%$ ) is well within the physiological range of $5 \%$ strain for cardiomyocytes. ${ }^{[46]}$ As expected the higher frequency stimulation display slightly lower actuation strains (2-3\% for $0.1 \mathrm{~Hz}$ and 1-2\% for $0.2 \mathrm{~Hz}$ ), but still physiological relevant. It was observed that for individual fibres the volume change varied independently across the sample, most likely due to variations in PPy(DBS) thickness and variation in ionic diffusion within the overall fibre mesh structure. The variable mechanical stimulation of the scaffold is beneficial due to the variable nature of the in vivo environment; variability in a 3D construct has been suggested to improve cardiomyocyte maturation. ${ }^{[47]}$ 
The differences in gene expression between stimulated and unstimulated iPS cells on 30 min ECP scaffolds can be so far found only for Oct4 (Figure 3e.ii), these findings are strongly suggestive that the iPS may undergo differentiation, in corroboration with the excellent cell viabilility. It is highly probable that optimization of stimulation protocol can lead to a more pronounced effect on cardiac differentiation, and with future in-depth analyses of stimulated cells the EMAF scaffold may prove an ability to differentiate iPS in cardiomyocytes.

Differences observed in the actin filament staining for the $10 \mathrm{~min}$ and $30 \mathrm{~min}$ ECP scaffolds may stem from the differences in the mechanical actuation applied to the iPS cells via the scaffolds. The 10 min ECP scaffolds do not actuate to a scale observable by optical microscopy, unlike the 30 min ECP scaffolds, and hence while there may be nanoscale volume changes the direct actuation provided is much lower compared to the thicker $30 \mathrm{~min}$ ECP scaffolds. Both scaffolds however will deliver electrical stimulation to the iPS, and hence it may be the difference in actuation that is affecting the actin filament elongation between the two materials. The effect of electrical stimulation on cells using PPy has been previously explored, ${ }^{[48-51]}$ but not for iPS cells and is an area for further exploration. The forces that the electroactive scaffold will apply to iPS cells is also an important factor to consider in relation to the mechanical strain of the scaffolds; if we assume that iPS cells have a Young's modulus in the range of 0.9 to $1.3 \mathrm{kPa}^{[52]}$ we can use a simplistic approximation to calculate the force range with the tensile stress applied from the mechanical actuation volume change, approximately 5 to $7 \mathrm{mN}$. This force is two orders of magnitude greater than typical forces associated with cardiomyocyte contractions and focal adhesions $(\sim 70 \mathrm{nN}),{ }^{[53]}$ and is a factor to take into consideration when evaluating iPS response to the mechanical actuation in future scaffold design.

\section{Conclusion}

Here we present a novel electro-mechanically active scaffold that can provide a microenvironment including electro-mechanical stimulation that may promote engraftment, 
differentiation and survival of stem cells by controlling the biophysical and biochemical micro-environments of transplanted cells and mimicking the structural architecture of the heart. The mechanical actuation of the scaffold is the first to demonstrate individual microfibre actuation within a scaffold structure, and will be able to provide encompassing, coherent physiological strain to individual cells, mimicking the cyclic mechanical flow and force within the heart. The EMAF scaffold is capable of supporting and directly stimulating iPS cells, with excellent cell viability after stimulation and a strong suggestion that the iPS could undergo differentiation. Further bio-experiments will aim to establish the effect of electromechanical stimulation on the differentiation of iPS into cardiomyocytes. Mechanical forces play an important role in the development, response, and differentiation of cells, ${ }^{[54]}$ hence creating a scaffold that provides dual electrical and mechanical stimulation in a 3D environment pushes the development of smart biomaterials for new therapies for cardiac tissue regeneration further forward.

\section{Experimental Section}

\section{Materials}

50:50 poly(lactic-co-glycolic acid) of mol wt 30000 - 60000 g mol-1 was obtained and used as received to prepare the electrospinning solution in chloroform. Pyrrole (Py) was obtained at $98 \%$ purity and then re-distilled to remove oligomers and impurities.

Dodecylbenzenesulfonic acid sodium salt (DBS) was obtained and used as received from TCI Europe N.V. All chemicals are supplied from Sigma Aldrich unless indicated otherwise. Electro-mechanically Active Scaffold Synthesis 50:50 poly(lactic-co-glycolic acid) was prepared as a 17.5\% wt/wt solution in chloroform. The PLGA solution was electrospun at a voltage of $20 \mathrm{kV}$ with a flow rate of $0.5 \mathrm{~mL} /$ hour. The electrospun PLGA fibres were then collected and dried over night to evaporate any remaining solvent. The fibres were then spin-coated with a solution of $5 \% \mathrm{wt} / \mathrm{wt}$ iron (III) 
chloride in methanol using a spincoater (Laurell Tech. Corp., USA). The FeCl3 coated fibres were then dried over night to evaporate any remaining solvent. The fibres are then exposed to pyrrole (Py) vapour in a sealed vessel at $50^{\circ} \mathrm{C}$ for $60 \mathrm{~s}$. For electropolymerisation the aqueous pyrrole solutions were prepared with $0.1 \mathrm{M}$ concentration of DBS (TCI Europe) and $0.1 \mathrm{M}$ Py. The VPP coated mesh was then placed into the aqueous pyrrole/dopant solution in a 3 point electrochemical cell and a constant potential of $0.67 \mathrm{~V}$ was applied to the electrochemical cell for 600 or $1800 \mathrm{~s}$. The ECP coated mesh was then lightly rinsed three times with DI water, dried gently with N2 gas, and stored in a Petri dish. All chemicals are supplied from Sigma Aldrich unless indicated otherwise. Electro-mechanically active scaffold synthesis was previously described in Gelmi et al. ${ }^{[55]}$

\section{Material Characterisation}

The scaffolds were sputter coated with gold (30 A) and examined in a LEO 1550 scanning electron microscope (Zeiss, Germany) with an electron beam energy of $5.02 \mathrm{kV}$. The iPS cells on scaffolds were prepared for SEM after being fixed to the fibre samples with formaldehyde. The fibre and iPS were then carefully rinsed with MilliQ water (18.1 $\Omega$ ), then dried via gradual ethanol dehydration and finally sputter coated with a gold layer (30 Å) for SEM imaging.

Fibre diameter analysis was performed using ImageJ software analysis to randomly select fibres for measurement with a minimum of 25 fibres per image.

The cyclic voltammetry measurements were performed in $7.4 \mathrm{pH}$ phosphate buffer solution (PBS) at an applied voltage range of $-1 \mathrm{~V}$ to $0.4 \mathrm{~V}, 3$ cycles, and scan rate $50 \mathrm{mV} / \mathrm{s}$. The PPy coated scaffolds were soaked in the PBS solution for 30 minutes prior to cyclic voltammetry measurements.

For morphological degradation the EMAF scaffolds were incubated in $7.4 \mathrm{pH}$ PBS for 7 days at $37{ }^{\circ} \mathrm{C}$ and $5 \% \mathrm{CO}_{2}$, with sections taken at intervals of 0 , 2, and 7 days from the same 
scaffold. For electroactivity degradation, the data was recorded in cell differential media during live cell stimulation (see detail below).

Mechanical actuation was recorded using bright field optical microscopy (Nikon Eclipse TiE, Netherlands) with biphasic potential stimulation $(0.2 \mathrm{~V}$ to $-1 \mathrm{~V})$ at three frequencies $(0.05$, 0.1 , and $0.2 \mathrm{~Hz}$ ). Analysis of the video recording was performed using an Image threshold macro to calculate the area of the fibres of video stills extracted from the recording at a rate of 1 frame per second (fps) for 0.05 and $0.1 \mathrm{~Hz}$, and 5 fps for $0.2 \mathrm{~Hz}$. Light intensity cross sections were taken across individual fibres and measured during oxidation and reduction for the first and last cycles at each stimulation frequency. Forces applied to stem cells by the EMAF scaffolds is approximated by $\mathrm{F}=\mathrm{EA} \mathrm{A}_{0} \mathrm{~L}$ where we assume that iPS cells have a Young's modulus (E) in the range of 0.9 to $1.3 \mathrm{kPa}^{[52]}$ the cross sectional area (A0) of the iPS is 100 $\mu \mathrm{m} 2$, and the actuating length change (L) is $6 \%$.

Induction and Culture of iPS Cells

Induced pluripotent stem (iPS) cells were generated from primary human dermal fibroblasts (provided by Dr. Gunnar Kratz, Linköping University) by retroviral induction of Oct4, Sox2, Klf4, and c-Myc transcription factors. Shortly, retroviruses with the 4 factors were independently produced by transfecting HEK 293 cells (X-tremGENE HP DNA Transfection Reagent, Roche) with vectors encoding for the human OCT4, SOX2, KLF4, and c-MYC, gag-pol plasmid pUMVC and pCMV-VSV-G envelope plasmid in DMEM containing 10\% FBS (PAA). 48, 72 and 96 hours after transfection viral supernatants were collected, filtered through a $0.45-\mu \mathrm{m}$ low protein binding PVDF filter (Millipore) and concentrated by centrifuging at $4000 \times \mathrm{g}$ for 1 hour at $4{ }^{\circ} \mathrm{C}$ using Amicon ${ }^{\circledR}$ Ultra Centrifugal Filter Devices (Millipore).

For reprogramming experiment, 50000 fibroblasts were seeded per well of a 6-well plate and infected on the next day with the mixture of retroviral concentrated supernatants in the 
presence of $4 \mu \mathrm{g} / \mathrm{ml}$ of hexadimethrine bromide (Sigma). Transduced fibroblasts were then incubated at $37{ }^{\circ} \mathrm{C}$ with $5 \% \mathrm{CO}_{2}$ for 6 days in DMEM medium (PAA) supplemented with $1 \mathrm{mM}$ valproic acid (Sigma) and $10 \mu \mathrm{M}$ ROCK inhibitor (Y-27632, Wako Reagent). 6 days after transduction fibroblasts were treated with accutase (Sigma) and seeded on the mitomycin-C treated MEF cells $\left(5.5 \times 104\right.$ cells $\left./ \mathrm{cm}^{2}\right)$ in Primate ES Cell Medium (ReproCELL) with $1 \mathrm{mM}$ valproic acid and $10 \mu \mathrm{M}$ ROCK inhibitor. Cells were then cultured in hypoxia conditions $\left(5 \% \mathrm{O}_{2}\right)$ with daily medium change. After approximately 2 weeks first round, ES-cell-like colonies with distinct edges were observed. iPS colonies were picked up enzymatically using $1 \mathrm{mg} / \mathrm{ml}$ Collagenase/Dispase (Roche), dissociated mechanically into smaller clumps, and plated in Primate ES Cell Medium onto fresh mitomycin-C treated MEF cells and cultured again in standard conditions $\left(37^{\circ} \mathrm{C}, 5 \% \mathrm{CO}_{2}, 21 \% \mathrm{O}_{2}\right)$. Pluripotency of iPS cells was confirmed by immunocytochemical staining for Oct4, Klf4, Nanog and alkaline phosphatase.

\section{Cardiac Differentiation}

IPS cells were differentiated to cardiomyocytes using the embryoid body (EB) method described previously by Zhang. ${ }^{[56]}$ Shortly, iPS cells were seeded onto MEFs and expanded for several days to reach the size of approximately 50-200 iPS cells per colony. IPS cells were then detached enzymatically by incubating with $1 \mathrm{mg} / \mathrm{mL}$ Collagenase/Dispase solution in ultralow attachment 6-well culture plates (Nunc) in suspension culture for 4 days. Differentiation medium, consisting of 80\% DMEM/F12 (Sigma), $1 \times$ MEM Non-essential Amino Acids (Gibco), 2 mM L-glutamine (Gibco), $0.1 \mathrm{mM} \beta$-mercaptoethanol (Sigma), and 20\% FBS (PAA), was used to initiate cardiac differentiation. During suspension culture, the medium was changed at day 1 followed by culture for another 3 days without medium change. Cells were then plated on scaffolds and cultured in differentiation medium (change 
daily) for next 10 days. Approximately 1500 cells within the EBs are estimated to be seeded onto the scaffolds.

Quantitative RT- PCR (PCR analysis)

For the real-time RT- PCR, total RNA was isolated from cells using the High Pure RNA Isolation Kit (Roche) according to manufacturer's protocol. Concentration of total RNA into each sample was determined using NanoDrop ${ }^{\mathrm{TM}}$ spectrophotometer (Thermo Scientific). For the cDNA synthesis 200 ng of total RNA templates was used and mixed with the master mix from Maxima ${ }^{\circledR}$ First Strand cDNA Synthesis Kit for RT-qPCR (Thermo Scientific) and loaded into the thermal cycler (CFX96 ${ }^{\mathrm{TM}}$ real-time PCR detection system, Biorad). The consequential cDNA synthesis reaction was employed first to produce a standard curve for RT-qPCR. Samples were incubated for 10 minutes at $25^{\circ} \mathrm{C}$ followed by 15 minutes at $50{ }^{\circ} \mathrm{C}$. The reaction was terminated by heating at $85{ }^{\circ} \mathrm{C}$ for 5 minutes. Next, $2 \mu$ of total cDNA was added to a $20 \mu$ reaction mix containing $\mathrm{iQ}^{\mathrm{TM}}$ SYBR ${ }^{\circledR}$ Green Supermix (Biorad) and 200 $\mathrm{nM}$ of each primers (Table S1). Triplicate reactions, for three biological samples were performed for each gene in a 96-well plate using a two-step amplification program of initial denaturation at $95^{\circ} \mathrm{C}$ for $3 \mathrm{~min}$, followed by 40 cycles of $95{ }^{\circ} \mathrm{C}$ for $15 \mathrm{~s}$ and $60{ }^{\circ} \mathrm{C}$ for $60 \mathrm{~s}$ using CFX96" ${ }^{\mathrm{TM}}$ real-time PCR detection system (Biorad). The specificity of each PCR product was checked by melting curve analysis. No nonspecific amplification or primerdimer was observed in any of the reactions. The relative quantification in gene expression was determined using the 2- $\Delta \Delta \mathrm{Ct}$ method 48 with GAPDH as an internal control gene. Semi quantitative RT-PCR was performed using DreamTaq Green PCR Master Mix (Fermentas) and then subjected to 1.5\% agarose gel electrophoresis. For the PCR analysis, the primers used are listed in Table S1.

Cell Viability Assay 
To quantify dead and live cells, LIVE/DEAD® Viability/Cytotoxicity Kit (Life Technologies) was used. Briefly, prior to the assay, cells on scaffolds were washed in PBS to remove serum esterase activity present in serum-supplemented growth media. Next, solution of $2 \mu \mathrm{M}$ calcein AM and $4 \mu \mathrm{M}$ EthD-1 in PBS was prepared and added to cells. Cells were incubated with dyes at room temperature for 20 minutes and then analyzed using Axio Vert.A1 (Carl Zeiss AG) inverted fluorescence microscope.

Quantitative Live/Dead Analysis

Numbers of dead and live cells were quantified using the ImageJ software and cell count plugin. At least four fields were counted per sample. No significant changes were found between tested samples.

\section{Actin Filaments Staining}

For actin staining cells were washed twice in PBS, fixed with $4 \%$ formaldehyde solution in PBS for 10 min at room temperature, washed again in PBS, permeabilized with $0.1 \%$ Triton X-100 for 5 min and stained with phalloidin-FITC conjugate (Invitrogen, Molecular Probes) for 20 min. DAPI was used for nuclear counter staining and images were captured using Axio Vert.A1 inverted fluorescence microscope.

\section{iPS Cell Stimulation}

The EMAF scaffolds were set into 6-well plates with Aluminium tape connecting to the scaffold. A cured PDMS layer was placed over the Al tape to insulate it in the cell media, and a 5 x 5 mm window over the EMAF scaffold sample. A stainless steel mesh was placed into the well to act as a counter-electrode during electrical stimulation, and removed once stimulation was complete. A silver wire pseudo-reference was inserted into the well during stimulation to complete the three point electrochemical cell. A PalmSens (Netherlands) potentiostat was used to apply a biphasic stimulation of $0.2 \mathrm{~V}$ and $-1 \mathrm{~V}$ at a frequency of 0.05 Hz for 600 s every 24 hours for 3 consecutive days. 
Statistical Analysis

Statistical significance for fibre diameter measurements was performed using a 2-tail T-test where $\mathrm{p}<0.05$. Statistical analysis of the live/dead quantification was performed using 1 way ANOVA where $\mathrm{p}<0.05$.

\section{Supporting Information}

Supporting Information is available from the Wiley Online Library or from the author.

\section{Acknowledgements}

Financial support for this project was received from Linköping University, Integrative Regenerative Medicine (IGEN) Center(post-doc grant), Swedish Research Council (VR2014-3079), COST-Action MP1003, Knut och Alice Wallenberg Commemorative Fund, GeCONiI (POIG.02.03.01-24-099/13) and the European Research Agency for EU FP7PEOPLE-2011-CIG-Marie Curie Actions-Career Integration Grant (CIG).

\section{References}

[1] A. S. Go, D. Mozaffarian, V. L. Roger, E. J. Benjamin, J. D. Berry, M. J. Blaha, S. Dai, E. S. Ford, C. S. Fox, S. Franco, Circulation 2014, 129, e28.

[2] E. Braunwald, The Lancet 2015, 385, 812.

[3] C. L. Mummery, R. P. Davis, J. E. Krieger, Science Translational Medicine 2010, 2, $27 \mathrm{ps} 17$.

[4] M. Gyongyosi, W. Wojakowski, P. Lemarchand, K. Lunde, M. Tendera, J. Bartunek, E. Marban, B. Assmus, T. D. Henry, J. H. Traverse, L. A. Moye, D. Surder, R. Corti, H. Huikuri, J. Miettinen, J. Wohrle, S. Obradovic, J. Roncalli, K. Malliaras, E. Pokushalov, A. Romanov, J. Kastrup, M. W. Bergmann, D. E. Atsma, A. Diederichsen, I. Edes, I. Benedek, T. Benedek, H. Pejkov, N. Nyolczas, N. Pavo, J. Bergler-Klein, I. J. Pavo, C. Sylven, S. Berti, E. P. Navarese, G. Maurer, A. Investigators*, Circ Res 2015, 116, 1346.

[5] C. L. Mummery, R. P. Davis, J. E. Krieger, Science Translational Medicine 2010, 2, 1.

[6] Z. Liu, J. Zhou, H. Wang, M. Zhao, C. Wang, Regenerative Medicine Research 2013, $1,6$.

[7] K. Takahashi, S. Yamanaka, Cell 2006, 126, 663.

[8] J. Leor, S. Aboulafia-Etzion, A. Dar, L. Shapiro, I. M. Barbash, A. Battler, Y. Granot, S. Cohen, Circulation 2000, 102, Iii.

[9] A. F. G. Godier-Furnémont, T. P. Martens, M. S. Koeckert, L. Wan, J. Parks, K. Arai, G. Zhang, B. Hudson, S. Homma, G. Vunjak-Novakovic, Proceedings of the National Academy of Sciences 2011, 108, 7974.

[10] L. Ghasemi-Mobarakeh, M. P. Prabhakaran, M. Nematollahi, K. Karbalaie, S. Ramakrishna, M. H. Nasr-Esfahani, International Journal of Polymeric Materials and Polymeric Biomaterials 2013, 63, 240.

[11] X. Zong, H. Bien, C.-Y. Chung, L. Yin, D. Fang, B. S. Hsiao, B. Chu, E. Entcheva, Biomaterials 2005, 26, 5330.

[12] C. Xu, R. Inai, M. Kotaki, S. Ramakrishna, Tissue Eng 2004, 10, 1160. 
[13] D. Kai, M. P. Prabhakaran, G. Jin, S. Ramakrishna, Journal of Biomedical Materials Research Part B: Applied Biomaterials 2011, 98B, 379.

[14] N. Baheiraei, H. Yeganeh, J. Ai, R. Gharibi, S. Ebrahimi-Barough, M. Azami, S. Vahdat, H. Baharvand, Journal of Biomedical Materials Research Part A 2015, 103, 3179.

[15] A. Borriello, V. Guarino, L. Schiavo, M. A. Alvarez-Perez, L. Ambrosio, Journal of Materials Science: Materials in Medicine 2011, 22, 1053.

[16] D. Ge, X. Liu, L. Li, J. Wu, Q. Tu, Y. Shi, H. Chen, Biochemical and Biophysical Research Communications 2009, 381, 317.

[17] A. Mihic, J. Li, Y. Miyagi, M. Gagliardi, S.-H. Li, J. Zu, R. D. Weisel, G. Keller, R.K. Li, Biomaterials 2014, 35, 2798.

[18] W. L. Stoppel, D. L. Kaplan, L. D. Black, Advanced drug delivery reviews 2016, 96, 135.

[19] V. Lundin, A. Herland, M. Berggren, E. W. H. Jager, A. I. Teixeira, PLoS One 2011, 6, e18624.

[20] J. Pelto, M. Bjorninen, A. Palli, E. Talvitie, J. Hyttinen, B. Mannerstrom, R. Suuronen Seppanen, M. Kellomaki, S. Miettinen, S. Haimi, Tissue Eng Part A 2013, 19, 882.

[21] A. Gelmi, M. K. Ljunggren, M. Rafat, E. W. H. Jager, Journal of Materials Chemistry B 2014, 2, 3860.

[22] E. W. H. Jager, O. Inganäs, I. Lundström, Science 2000, 288, 2335.

[23] E. Ghafar-Zadeh, J. R. Waldeisen, L. P. Lee, Lab on a Chip 2011, 11, 3031.

[24] P. C. Dartsch, E. Betz, Basic Research in Cardiology 1989, 84, 268.

[25] W. J. Li, C. T. Laurencin, E. J. Caterson, R. S. Tuan, F. K. Ko, Journal of Biomedical Materials Research 2002, 60, 613.

[26] J. Yu, A. R. Lee, W. H. Lin, C. W. Lin, Y. K. Wu, W. B. Tsai, Tissue engineering. Part A 2014.

[27] K. A. Athanasiou, G. G. Niederauer, C. M. Agrawal, Biomaterials 1996, 17, 93.

[28] E. Smela, J. Micromech. Microeng. 1999, 9, 1.

[29] Q. Pei, O. Inganäs, Journal of Physical Chemistry 1993, 97, 6034.

[30] Q. Pei, O. Inganäs, Journal of physical chemistry 1992, 96, 10507.

[31] E. W. H. Jager, E. Smela, O. Inganäs, I. Lundström, Synthetic Metals 1999, 102, 1309.

[32] Y. You, B.-M. Min, S. J. Lee, T. S. Lee, W. H. Park, Journal of Applied Polymer Science 2005, 95, 193.

[33] A. Gelmi, M. J. Higgins, G. G. Wallace, Biomaterials 2010, 31, 1974.

[34] D. Melling, S. Wilson, E. W. H. Jager, Smart Materials \& Structures 2013, 22, 104021.

[35] M. J. M. Jafeen, M. A. Careem, S. Skaarup, Ionics 2010, 16, 1.

[36] E. Smela, N. Gadegaard, Advanced Materials 1999, 11, 953.

[37] M. Omastová, M. Trchová, J. Kovářová, J. Stejskal, Synthetic Metals 2003, 138, 447.

[38] L. F. Warren, D. P. Anderson, Journal of The Electrochemical Society 1987, 134,

101.

[39] A. Gelmi, M. J. Higgins, G. G. Wallace, Small 2013, 9, 393.

[40] P. J. Molino, M. J. Higgins, P. C. Innis, R. M. I. Kapsa, G. G. Wallace, Langmuir 2012, 28, 8433.

[41] Q. Pei, O. Inganaes, The Journal of Physical Chemistry 1992, 96, 10507.

[42] K. Kurpinski, J. Park, R. G. Thakar, S. Li, Molecular and Cellular Biomechanics 2006, 3, 21.

[43] J. S. Park, J. S. Chu, C. Cheng, F. Chen, D. Chen, S. Li, Biotechnology and Bioengineering 2004, 88, 359. 
[44] K. Svennersten, M. Berggren, A. Richter-Dahlfors, E. W. H. Jager, Lab on a Chip 2011, 11, 3287.

[45] F. Chowdhury, S. Na, D. Li, Y.-C. Poh, T. S. Tanaka, F. Wang, N. Wang, Nat Mater 2010, 9, 82.

[46] A. Kamgoué, J. Ohayon, Y. Usson, L. Riou, P. Tracqui, Cytometry Part A 2009, 75, 298.

[47] K. Y. Morgan, L. D. Black, 3rd, Journal of tissue engineering and regenerative medicine 2014.

[48] L. Forciniti, J. Ybarra Iii, M. H. Zaman, C. E. Schmidt, Acta Biomaterialia 2014, 10, 2423.

[49] W.-W. Hu, Y.-T. Hsu, Y.-C. Cheng, C. Li, R.-C. Ruaan, C.-C. Chien, C.-A. Chung, C.-W. Tsao, Mater. Sci. Eng. C 2014, 37, 28.

[50] K. J. Gilmore, M. Kita, Y. Han, A. Gelmi, M. J. Higgins, S. E. Moulton, G. M. Clark, R. Kapsa, G. G. Wallace, Biomaterials 2009, 30, 5292.

[51] C. E. Schmidt, V. R. Shastri, J. P. Vacanti, R. Langer, Proc. Natl. Acad. Sci. USA 1997, 94, 8948.

[52] K. E. Hammerick, Z. Huang, N. Sun, M. T. Lam, F. B. Prinz, J. C. Wu, G. W.

Commons, M. T. Longaker, Tissue Engineering Part A 2010, 17, 495.

[53] N. Q. Balaban, U. S. Schwarz, D. Riveline, P. Goichberg, G. Tzur, I. Sabanay, D. Mahalu, S. Safran, A. Bershadsky, L. Addadi, B. Geiger, Nature Cell Biology 2001, 3, 466. [54] M. A. Wozniak, C. S. Chen, Nat Rev Mol Cell Biol 2009, 10, 34.

[55] A. Gelmi, J. Zhang, A. Cieslar-Pobuda, M. K. Ljunngren, M. J. Los, M. Rafat, E. W. H. Jager, "Electroactive 3D materials for cardiac tissue engineering", 2015.

[56] J. Zhang, G. F. Wilson, A. G. Soerens, C. H. Koonce, J. Yu, S. P. Palecek, J. A. Thomson, T. J. Kamp, Circulation Research 2009, 104, e30. 

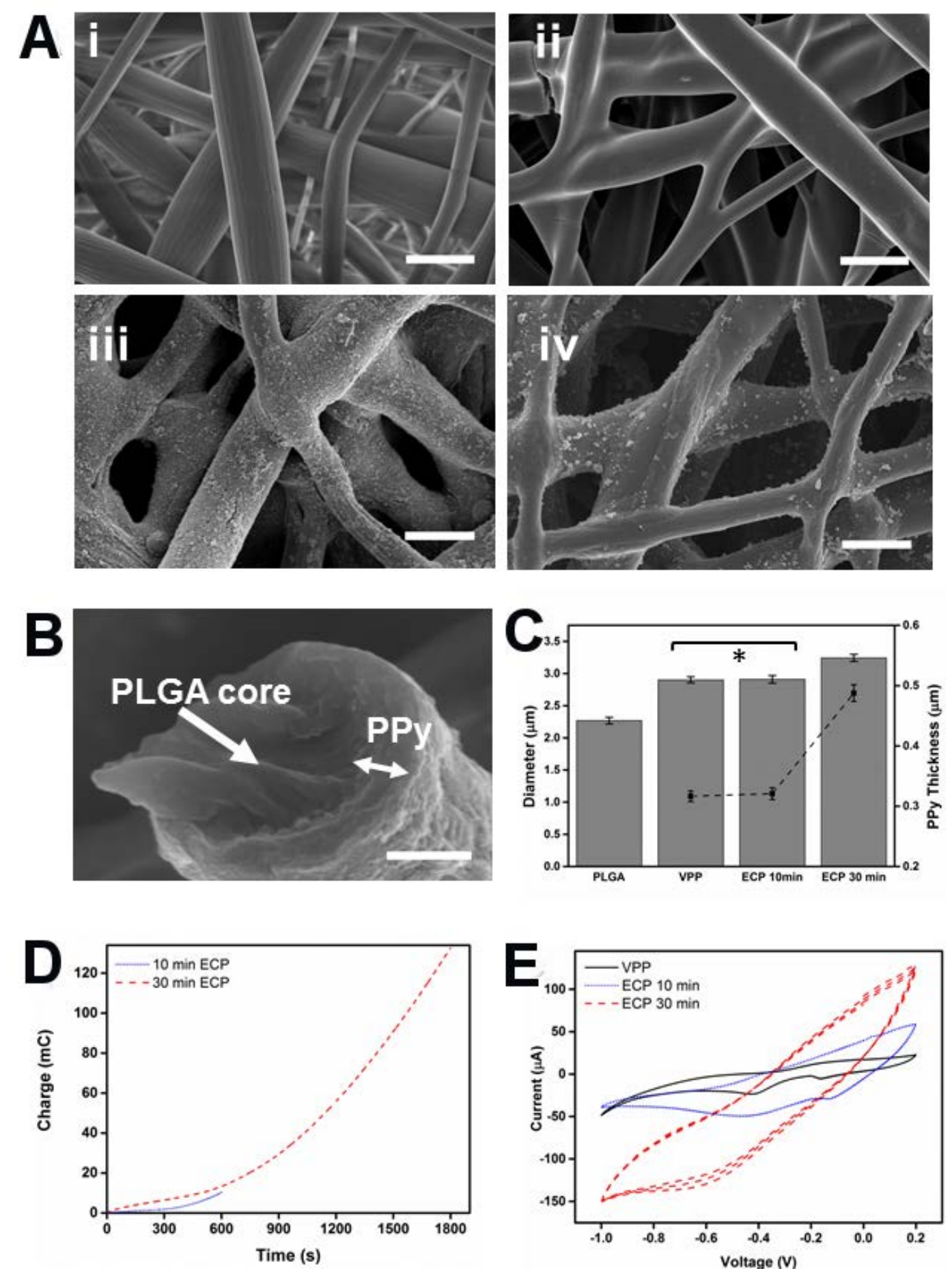

Figure 1. EMAF characterisation. (A) SEM micrographs of PLGA fibres (i) uncoated, (ii) VPP coated, (iii) 10 min ECP PPy(DBS)-coated, and (iv) 30 min ECP PPy(DBS)-coated. Scale bar represents $5 \mu \mathrm{m}$. (B) Cross-sectional view of $30 \mathrm{~min}$ ECP PPy(DBS) fibre with PLGA core and PPy coating marked with arrows. Scale bar represents $500 \mathrm{~nm}$. (C) Diameter (left axis) and calculated PPy thickness (right axis) of PLGA and each coating step. * marks insignificant difference $(\mathrm{p}<0.05)$. (D) Representative synthesis charge vs time for 10 and 30 min ECP, showing PPy deposition onto the fibres. (E) Representative CVs for VPP, $10 \mathrm{~min}$ and 30 min ECP PPy(DBS) showing increasing PPy thickness. 


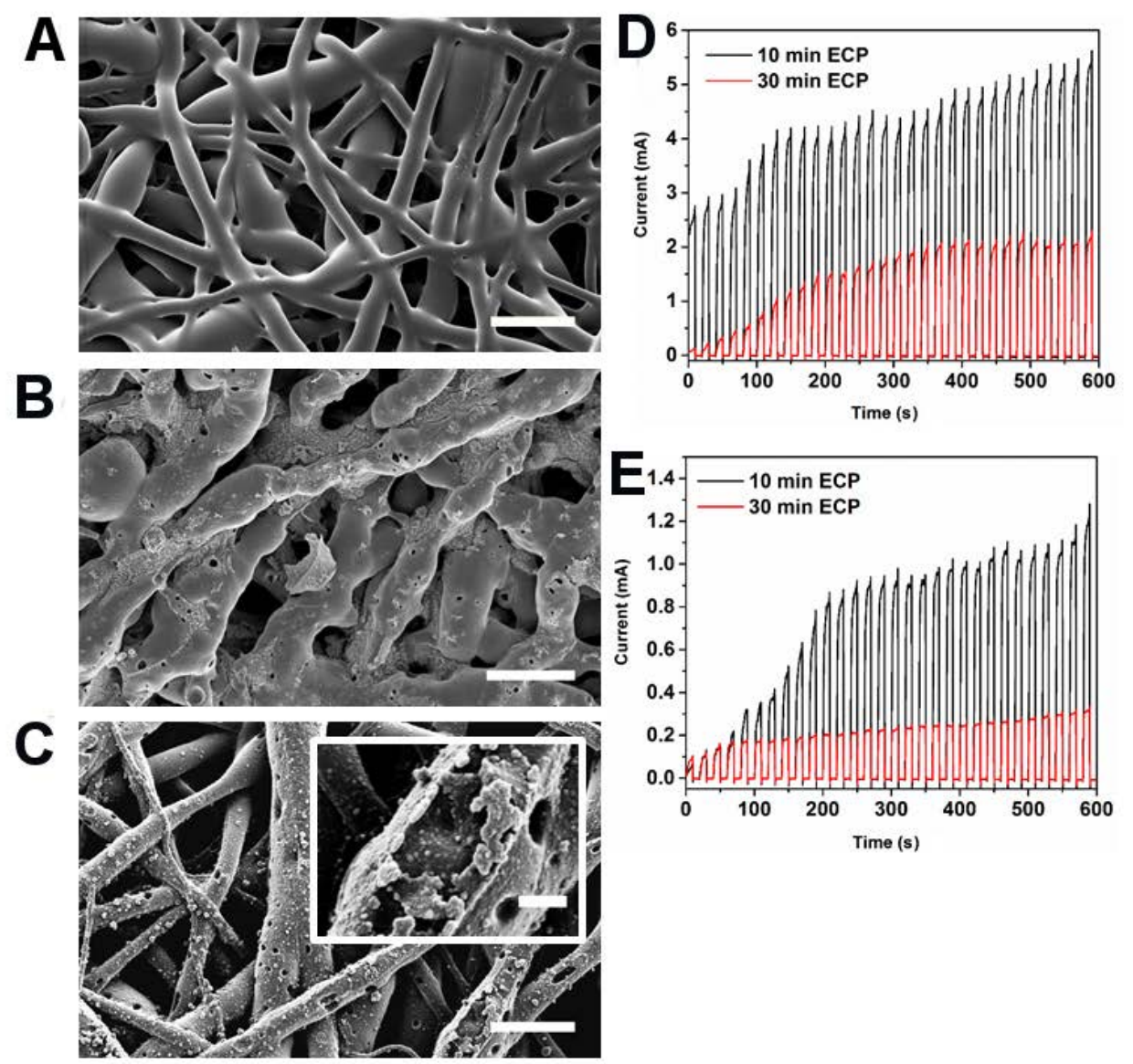

Figure 2. Degradation characterization of EMAF. SEM micrographs of fibres after 7 days in PBS at $37^{\circ} \mathrm{C}$ and $5 \% \mathrm{CO}_{2}$ (A) PLGA, (B) 10 min ECP PPy(DBS), and (C) 30 min ECP $\mathrm{PPy}(\mathrm{DBS})$. Scale bars represent $10 \mu \mathrm{m}$ (insert $\mathrm{C} 2 \mu \mathrm{m}$ ). A representative current response of 10 min (black) and 30 min (red) ECP coated fibres from $0.05 \mathrm{~Hz}$ biphasic voltage stimulation $(0.2 \mathrm{~V}$ to $-1 \mathrm{~V})$ was compared after (D) initial stimulation (total 3 days in differentiation media), and (E) final stimulation (3 consecutive days stimulation, total 7 days in differentiation media). 

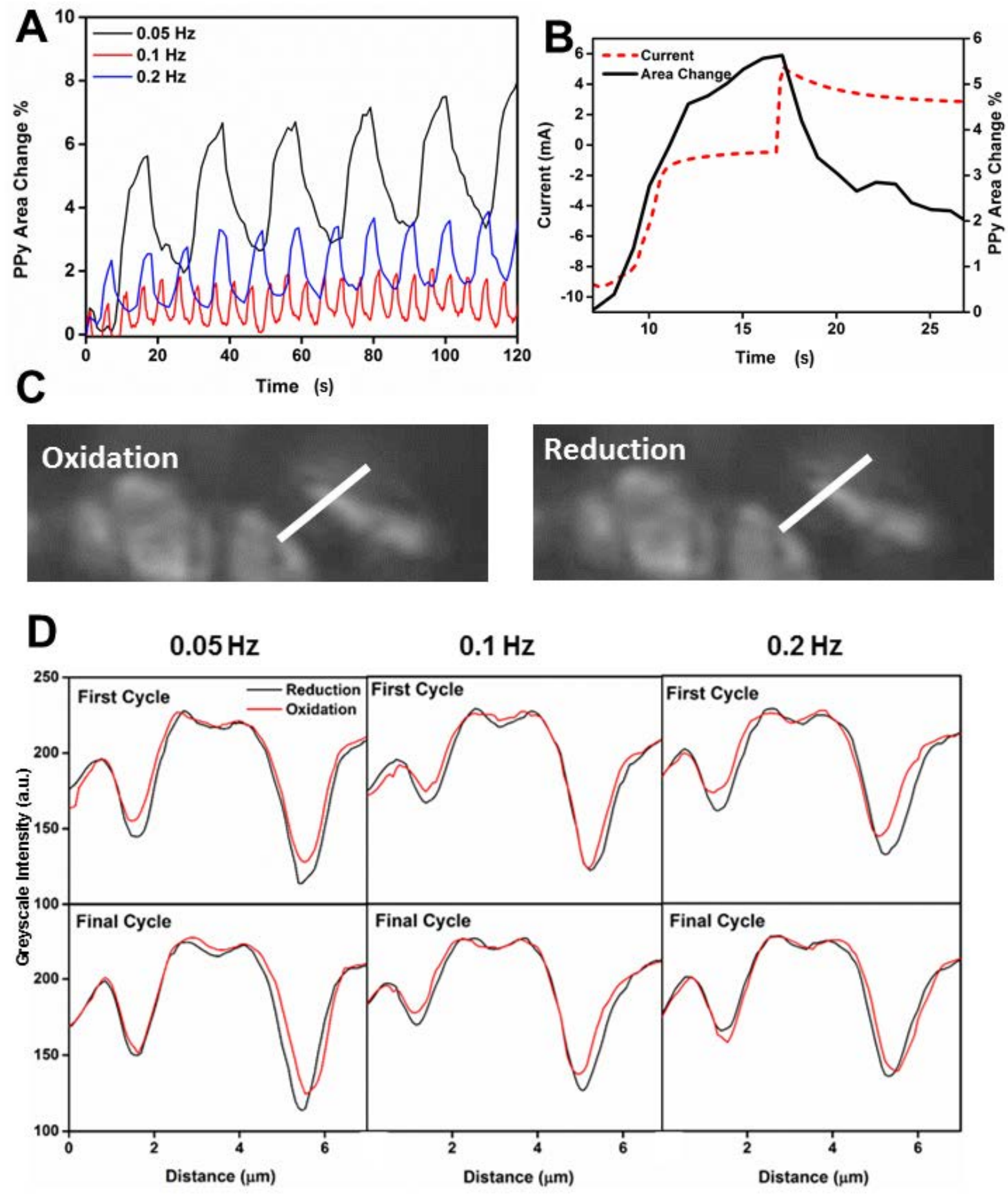

Figure 3. Mechanical actuation of EMAF. (A) PPy area change percentage using optical video during applied stimulation on 30 min ECP PPy(DBS) coated fibres in PBS, with a biphasic potential waveform at $0.05 \mathrm{~Hz}$ (black), $0.1 \mathrm{~Hz}$ (blue), and $0.2 \mathrm{~Hz}$ (red). (B) Current response of 30 min ECP PPy(DBS) and simultaneous PPy area change during $0.05 \mathrm{~Hz}$ applied stimulation. (C) Representative stills taken from the optical video recording during $0.05 \mathrm{~Hz}$ stimulation, with (D) cross sections taken from 3C (white line) showing the greyscale intensity change in both fibre diameter as well as fibre-to-fibre spacing ("pore size”) for0.05, 0.1, and $02 \mathrm{~Hz}$ stimulation. 


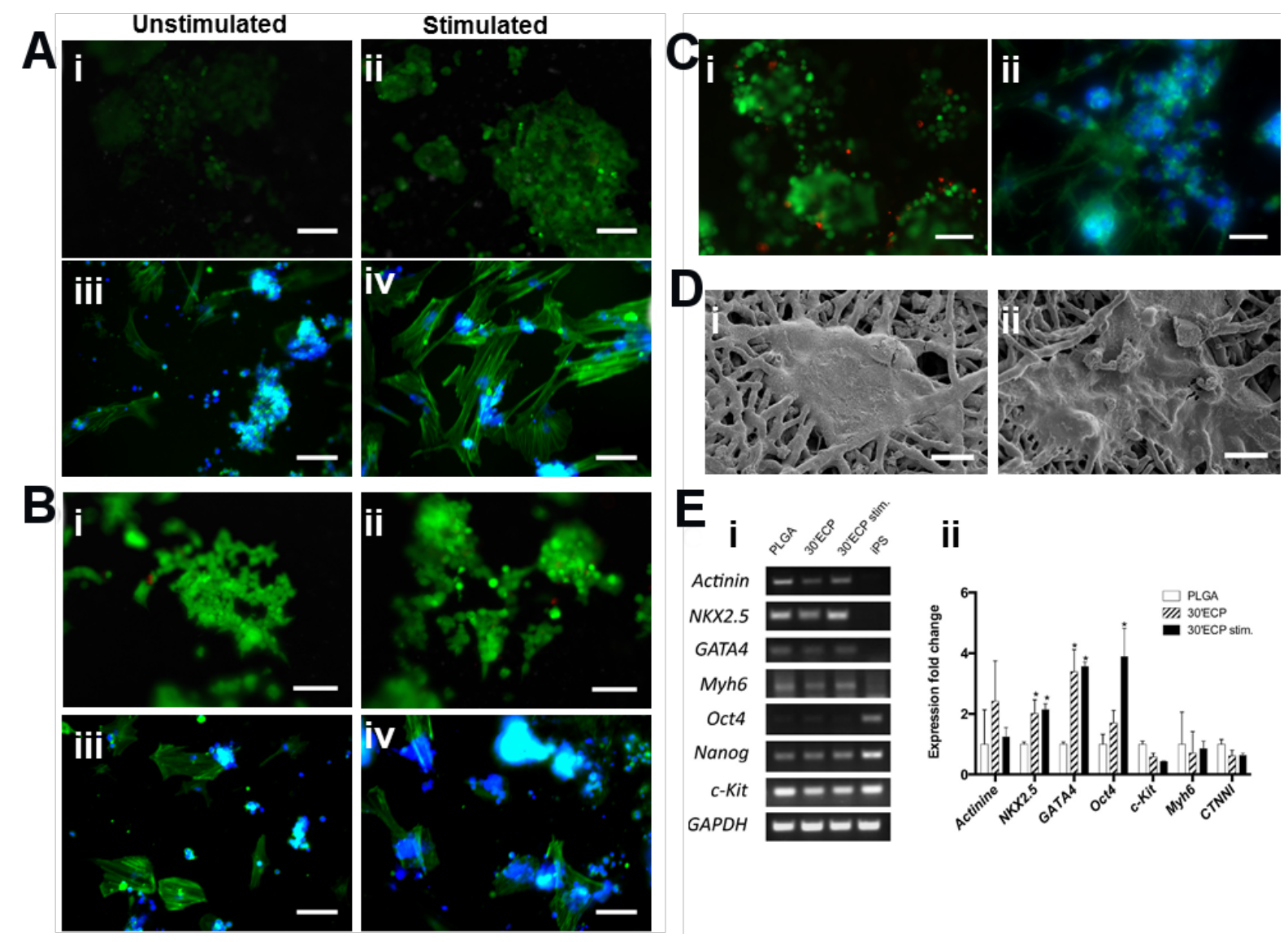

Figure 4. Biological analysis of iPS. Representative images of iPS cells fixed on (A) 10 min ECP, (B) 30 min PPy(DBS) and (C) PLGA scaffolds after 7 days growth. For the stimulated and unstimulated ECP scaffolds (A, B) the iPS were stained for (i, ii) live/dead (quantitative results in Figure S1) and (iii, iv) actin filaments for comparison. The uncoated PLGA (C) was also stained for (i) live/dead and (ii) actin. Scale bars represent $100 \mu \mathrm{m}$. (D) iPS cells fixed and imaged in SEM with (i) unstimulated and (ii) stimulated 10 min ECP scaffolds. Scale bars represent $20 \mu \mathrm{m}$. (E) Expression of cardiomyocyte-specific genes (Actinin, NKX2.5, GATA4, Myh6, c-kit) and stemness genes (Oct4, Nanog) in differentiating iPS cells grown on uncoated PLGA and 30 min ECP PPy (DBS) (with and without stimulation). Results from (i) semi-quantitative RT-PCR and (ii) quantitative real time RT-qPCR. * represents statistically significant difference in gene expression between PLGA and 30 min ECP $\mathrm{PPy}(\mathrm{DBS}),(\mathrm{P}<0.05)$. Data representative for 3 independent experiments. 
Here were present a new type of smart cardiac patch material, the electromechanically active fibre scaffold. The scaffold is capable of delivering electrical and mechanical stimulation to individual cells, and demonstrates controlled volume change actuation. The scaffold is non-cytotoxic and may enhance the cardiac differentiation of human induced pluripotent stem cells.

A. Gelmi, A. Cieslar-Pobuda, E. de Muinck, M. Los, M. Rafat, E. W.H. Jager*

Direct mechanical stimulation of stem cells: a beating electro-mechanically active scaffold for cardiac tissue engineering

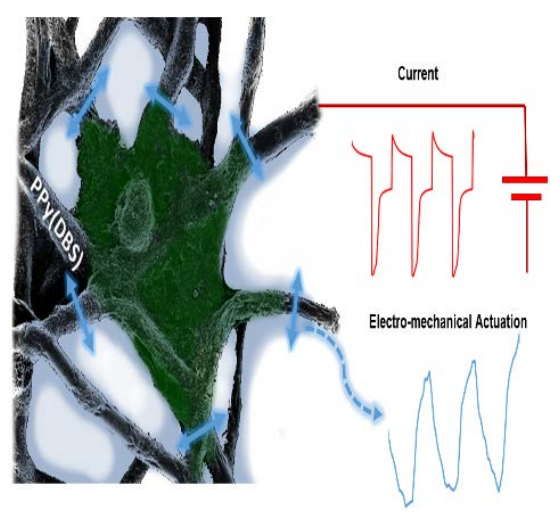




\section{Supporting Information}

Direct mechanical stimulation of stem cells: a beating electro-mechanically active scaffold for cardiac tissue engineering

Amy Gelmi, Artur Cieslar-Pobuda, Ebo de Muinck, Marek Los, Mehrdad Rafat, Edwin W.H. Jager*

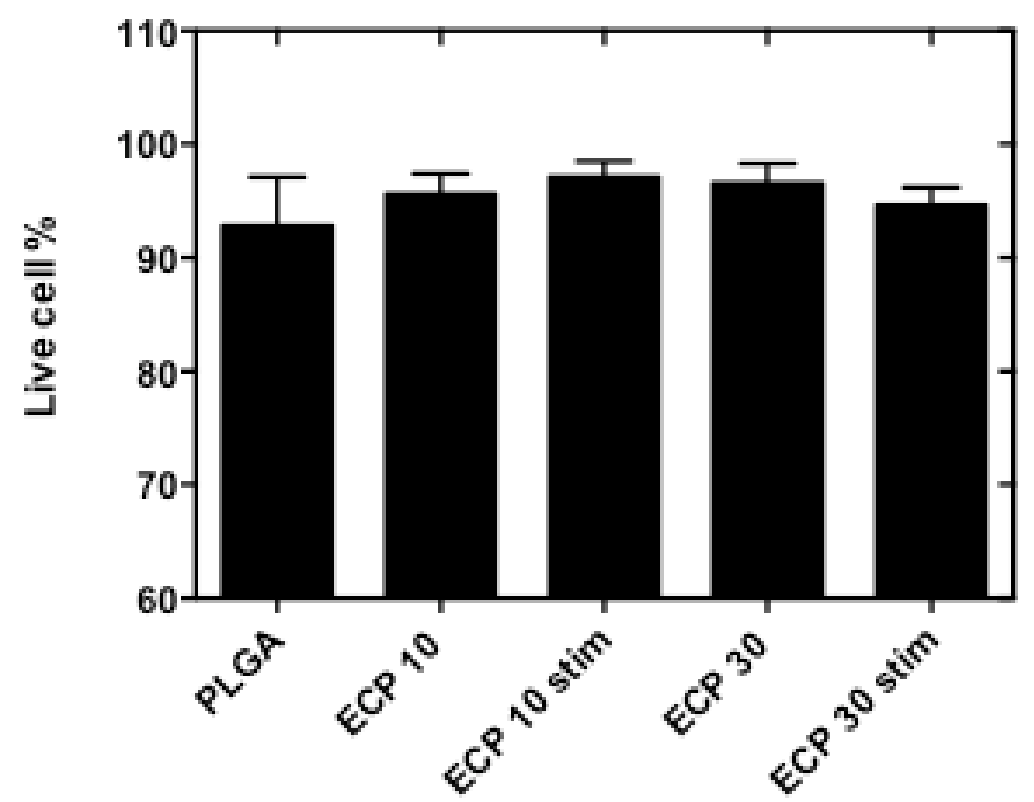

Figure S1: Quantitative live cell count percentage for PLGA, unstimulated ECP 10 and 30 min coated, and stimulated ECP 10 and 30 min coated scaffolds.

Table S1: PCR primers used for analysis of iPS

\begin{tabular}{|c|c|c|}
\hline Primer & Forward & Reverse \\
\hline GATA4 & 5'-AGCTCCGTGTCCCAGACG-3' & 5’-TCTGTGGAGACTGGCTGACG-3’' \\
\hline c-kit & $\begin{array}{l}\text { 5'-ATTCCCAGCCCATGAGTCCTTGA- } \\
\text { 3' }\end{array}$ & 5’-ACACGTGGAACACCAACATCCT-3’ \\
\hline CTNNI & 5’-CCAACTACCGCGCTTATGC-3' & 5'-CTCGCTCCAGCTCTTGCTTT-3' \\
\hline NKX2-5 & $\begin{array}{l}\text { 5’- } \\
\text { GCGATTATGCAGCGTGCAATGAGT-3' }\end{array}$ & $\begin{array}{l}\text { 5’- } \\
\text { AACATAAATACGGGTGGGTGCGTG-3' }\end{array}$ \\
\hline Actinin & 5’-GGCGTGCAGTACAACTACGTG-3’' & 5’-AGTCAATGAGGTCAGGCCGGT-3’' \\
\hline MYH6 & 5’-AGATCATCAAGGCCAAGGCA-3’' & 5’-CGCTGGGTGGTGAAATCATT-3’' \\
\hline Oct4 & 5’-TCTCGCCCCCTCCAGGT-3’' & 5’-GCCCCACTCCAACCTGG-3’' \\
\hline Nanog & 5'-AGAAGGCCTCAGCACCTAC-3' & 5'-GGCCTGATTGTTCCAGGATT-3' \\
\hline GAPDH & 5'-TCAACTACATGGTTTACATGTTC-3' & 5’-GATCTCGCTCCTGGAAGAT-3’' \\
\hline
\end{tabular}

Movie S1: Example footage of 30min coated PPy(DBS) EMAF scaffold, at 0.05, 0.1, and 0.2 Hz. Playback is increased to $32 x$. 